\title{
Interactive tabletops in education
}

\section{Pierre Dillenbourg \& Michael Evans}

International Journal of ComputerSupported Collaborative Learning An Official Publication of the

International Society of the Learning Sciences

ISSN 1556-1607

Volume 6

Number 4

Computer Supported Learning (2011) 6:491-514

DOI 10.1007/s11412-011-9127-7

\section{INTERNATIONAL JOURNAL OF \\ COMPUTER-SUPPORTED COLLABORATIVE LEARNING}

Volume 5, Issue 1, March 2010

EXECUTIVE EDITORS

Friedrich Hesse

Gerry Stahl

ASSOCIATE EDITORS

Tak-Wai Chan

Naomi Miyake

Claire O'Malley

Daniel D. Suthers

Barbara Wasson

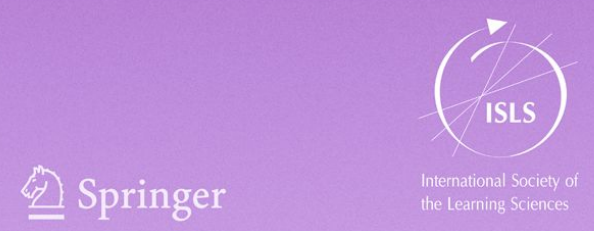

Springer 
Your article is protected by copyright and all rights are held exclusively by International Society of the Learning Sciences, Inc.;

Springer Science + Business Media, LLC. This e-offprint is for personal use only and shall not be self-archived in electronic repositories. If you wish to self-archive your work, please use the accepted author's version for posting to your own website or your institution's repository. You may further deposit the accepted author's version on a funder's repository at a funder's request, provided it is not made publicly available until 12 months after publication. 


\title{
Interactive tabletops in education
}

\author{
Pierre Dillenbourg • Michael Evans
}

Received: 23 February 2011 / Accepted: 11 July 2011 /

Published online: 21 August 2011

(C) International Society of the Learning Sciences, Inc.; Springer Science + Business Media, LLC 2011

\begin{abstract}
Interactive tabletops are gaining increased attention from CSCL researchers. This paper analyses the relation between this technology and teaching and learning processes. At a global level, one could argue that tabletops convey a socio-constructivist flavor: they support small teams that solve problems by exploring multiple solutions. The development of tabletop applications also witnesses the growing importance of face-to-face collaboration in CSCL and acknowledges the physicality of learning. However, this global analysis is insufficient. To analyze the educational potential of tabletops in education, we present 33 points that should be taken into consideration. These points are structured on four levels: individual user-system interaction, teamwork, classroom orchestration, and socio-cultural contexts. God lies in the details.
\end{abstract}

Keywords tabletop tangible $\cdot$ ubiquitous

\section{Introduction}

This paper is an introduction to a "flash theme" that the ijCSCL journal will develop over several issues: the use of interactive tabletop environments in education. The theme originates from a workshop on the same topic, which was held during the second "Alpine Rendez-Vous" (see the acknowledgment section).

An interactive tabletop is a computer interface that, as its name indicates, resembles a table: it is usually a horizontal (sometimes oblique) surface and usually is large enough to allow several users to interact simultaneously. The users' inputs are captured through the position of their fingers and of dedicated objects through a broad variety of techniques

P. Dillenbourg $(\square)$

EPFL, Lausanne, Switzerland

e-mail: pierre.dillenbourg@epfl.ch

M. Evans

Virginia Tech, Blacksburg, VA, USA

e-mail: mae@vt.edu 
(capacity grids; cameras capturing physical markers, finger contact points, or finger shapes; radio signals; RFID readers; etc.). The system output is displayed on the tabletop surface by LCD screens or by beamers (computer projectors) placed below or above the surface. New modes of input and output continue to be invented at a brisk pace.

Interactive tabletop technologies are sufficiently stable to support the industrialization of tabletop environments (many commercial products have appeared in the last five years) as well as the construction of custom-built tabletops using open-source drivers. Despite their variety, tabletop environments are sufficiently different from other interface categories (keyboard and mouse, haptic devices, audio, mobile, etc.) to deserve a specific analysis of their educational uses and implications.

As many novel technologies have done in the past, tabletops raise optimistic expectations on how they could change education. Nevertheless, we make clear that tabletop environments are not a panacea for improving teaching and learning. Despite this reservation, they convey novelty in two ways. First, tabletops have a specific educational flavor. While most CSCL environments are designed for on-line activities, tabletops are designed for co-located teamwork. Even if some on-line functionality is integrated in some tabletops, it generally constitutes an enrichment of face-to-face interaction rather than the central activity. Tabletop devices illustrate the evolution of CSCL from virtual spaces to the physical realm (touching objects or co-learners, conveying intention through gesture and posture, etc.), following to a noticeable degree the vision of Marc Weiser (1991) who predicted that the physical world would be imbued with computational media and communication technologies. Second, tabletops have a set of specific affordances, including the ability to physically support objects and to afford co-located collaboration and coordination. This paper analyzes both the global flavor and the specific affordances, but starts by stressing the need to avoid over-expectations.

\section{Preamble: Skeptical enthusiasm}

The world of interactive tabletops for education is still immature. However, we can learn from similar technological pushes. Over four decades, two mistakes have been repeated each time a new technology is introduced in education: over-generalization and over-expectation.

Over-generalization results from attributing the learning effects demonstrated in a specific instance of a technology to the entire technology. Statements regarding "the effectiveness of computer-based education" illustrate over-generalization. A more balanced position is that there is a wide variety of educational software on the market, some being effective and some not. Moreover, the same environment can be effective or not according to the way it is used in the classroom (Evans and Wilkins 2011): Learning outcomes depend upon how a teacher exploits the environment to bring specific students to reach specific objectives. For instance, while 'personal response systems' have been experimentally shown to be effective (Knight and Wood 2005), lessons fail if the questions raised by the teacher do not capture the students' interests. Media effects are a myth.

Over-expectation results from the enthusiasm triggered by any novel technology. At the onset, many educational promises are offered, stoking expectation beyond what any technology could ever deliver. A technology by itself does not turn students into smart, motivated knowledge producers. It requires contextualization, pedagogical goal setting, and fitting into the larger processes of learning. Therefore, key affordances of a technology include how teachers can appropriate it, how it can help to engage the learners, how the environment can be shaped to their goals, and how compatible it is to the many practical 
constraints in a learning environment. It is important to avoid over-expectation because it inevitably generates disappointment and skepticisms that are difficult to recover from. Cuban's (2003) work has demonstrated this known issue with claims regarding computer technology adoption and diffusion for quite some time.

Interactive tabletops are novel, original, and exciting. Yet, they will not by themselves radically change educational practice. Some tabletop environments will be effective while others will not. This may seem trivial, but as this paper opens a special thread on interactive tabletops it may be useful to repeat that technologies do not offer intrinsic educational effectiveness; rather, they have designed affordances. The aim of this introductory paper is precisely to analyze these affordances.

\section{Tabletop environments}

As its name indicates, the main feature of a tabletop environment is that a horizontal surface is used as input and as output to/from a digital environment. The most frequent input is a set of postions on the table provided by pointing directly to these locations (while with computer mice, the space of mouse movements is dissociated from the display space). We can label this direct interaction. Ways to select a table position with direct interaction vary:

1. Touch interfaces: The position of fingers is detected (1) as a contact point between conductivity layers, (2) by an infrared camera placed below and detecting heat points, (3) by a camera placed above where computer vision methods recognize fingers. Although this may be similar to a mouse click, there are many differences. Users apply their fingers to select, rotate, move and rescale digital objects (pictures, icons, buttons, shapes, etc.) displayed on the table. These interfaces are referred to as 'multi-touch' since they support the synchronous detection of multiple points.

2. Tangible objects: The position of tangible objects on the surface is detected by a camera placed above/below the surface by recognizing the objects as such by using "fiducial markers" (reference images such as ARTags) pasted on the objects. Other tabletops detect radio frequency (RFID) tags embedded within the objects. Since objects are on the same horizontal plane, the system reads only their horizontal position and orientation. Some objects are figurative (e.g., a tiny shelf representing a real shelf in a warehouse - see below) while some objects are iconic (e.g., a block with an eraser label to erase displayed objects) or symbolic, referencing parametric operations (see TanTab System below).

3. Electronic pen: Pens (or styli) are specific instances of tangible objects enabling the fine manipulations necessary to write or draw on the table. The position of the pen is recognized by radio signals or by a camera embedded in the pen which recognizes an underlying texture that human eyes do not perceive (e.g., the Annoto technology).

4. Paper-interfaces: Paper sheets placed on the surface constitute another category of tangible object with different properties (see Thinker Sheets below). They cannot only be moved and rotated, but also folded and annotated.

5. Gestural interfaces: In contrast to touch interfaces, gestural interfaces do not require direct interaction or contact with the tabletop. Using cameras, the system is able to track movements of hands for gestures to include sorting, collecting, drag-and-drop, and delegating ( $\mathrm{Li}$ et al. 2007). In these set-ups, it should be noted that the tabletop is often positioned as a control panel to coordinate other displays, which may make it a unique treatment in this list. 
6. Keyboard and mouse: Although this is not common (unless used for testing and calibration), there is no reason why tabletop users should not be allowed to use keyboards and mice. Using a pen for writing and fingers for pointing have advantages, but also drawbacks in terms of speed and precision that justify complementing tabletops with traditional input devices. For example, the SMART Table, an off-theshelf tabletop produced by SMART Tech, supports standard keyboard and mouse to facilitate teacher selection and set up of activities for learners. Our point is that multitouch should not result in interface dogma.

The outputs of tabletops are digital images displayed through an LCD display or beamed directly to a surface. Depending on the configuration, the image is beamed either from above or below. When suspended above, the beamer shines down on the surface (or a suspended mirror reflects the beamer projection). Alternatively, the image is beamed from below, i.e. the beamer is integrated into the table. In both cases, mirrors are often used to increase focal distance. Both approaches have pros and cons. Beaming from above allows projection on any surface, even if students manipulate water, sand, etc.. Beaming from above also allows augmented reality, i.e. beaming on the top of objects (tangibles, paper sheets) placed on the surface. In addition, the amount of light projected by the beamer stabilizes the lighting conditions for the image-processing algorithms. Conversely, projecting from above raises issues such as occlusion and shadows, as explained hereafter.

A major difference between tabletops and desktops is that multiple users have different viewpoints around the display: several solutions have been explored to cope with this, such as duplicating the display for different orientations (Africano et al. 2004; Shen et al. 2004a, b). Some systems include secondary displays such as vertical displays for collective reflection or individual displays on a tablet or PDA as private spaces.

The design of the tabletop environment varies in many ways: the size of the table, its shape (rectangular or circular), its texture (glass, synthetic), fixed or not (users can change the angle), its height (users can sit or stand), its angle (horizontal or oblique) as well as ergonomic features (users can place their legs below the table). These important ergonomic features often serve the technology as opposed to being justified by the instructional goals.

Finally, the tabletop environment is overall custom-designed digital equipment running specific software. In its current infancy, which still includes more demos than useful applications, the most frequent tabletop applications include navigating maps, sorting pictures, cards, or objects, and playing or composing music. The novelty makes tabletops attractive for exhibitions, public kiosks, and art performances. Inventing new applications, meaningful for education and validating them empirically is a primary challenge for the CSCL community that we address in this article.

\section{Examples of educational tabletops}

Tabletop environments have been used across many educational contexts. Early examples include the NIMIS environment used in elementary schools for reading instruction (Hoppe et al. 2000). Given the apparent "naturalness" of interactions, tabletop environments have often been designed for children, but there also exist applications for a range of age groups. The disciplines covered by these environments include physics, mathematics, logistics and art. We present here select examples of learning tasks based on tabletop environments; some will be presented in detail in coming issues of this journal. 
One of the earliest reported efforts in the CSCL literature is the "Envisionment and Discovery Collaboratory" (EDC), an interactive tabletop environment founded on principles of co-located, inquiry- and interest-driven collaboration (Arias et al. 2000; Eden 2002; Eden et al. 2002). The EDC environment, a project to enhance informed participation, is comprised of an interactive whiteboard situated horizontally on which simulations can be projected from above. Physical objects are used as inputs for the system. One application of the EDC is urban planning, where representatives of and citizens from the community collaborate on a shared model of a neighborhood, interacting with a software-driven simulation using the physical representations, including buildings and landscape features. A second vertical interactive whiteboard is used to present supplemental information related to the focus of discussion and collaboration (Eden 2002, p.402). An informal assessment of the EDC system illustrates limitations at the time, including singleuser input (requiring turn taking), insufficient detection of objects (requiring the user to place-then-press in an unnatural fashion), and a disconnect between the mental model of the simulation and the interface (requiring concerted effort from the end-user). In response to these concerns, the EDC was adapted to accommodate a Participate-in-Action-Board (PitABoard), which allowed for multiple touch points, automatic sensing of physical objects, and parallel interactions. Using the guiding principle of "naïve manipulability" (Eden 2002, p.404), developers anticipated a system that serves as a fluid medium to support co-located inquiry and communication. This principle was supported with a participatory-design focus, where stakeholders contributed to the development and evaluation of the EDC system (Eden et al. 2002). A primary contribution of this work was to lay a foundation for much work cited in this article and continuing to this day.

The SynergyNet project (Fig. 1) has developed a classroom environment with networked multi-touch tables. Small groups of 10-11 year-old children undertook a history task where they were instructed to connect various pieces of information about a mining accident to reach a consensus about who had been responsible. The design aimed to enable learners and a teacher to easily share digital resources and information (Hatch et al. 2009). In addition, aspects of the process of learning can also be shared by moving more easily between whole class and small group activity (Blatchford et al. 2003; Nussbaum et al. 2009). The intention is to develop uptake (Nystrand et al. 2003) and integration of learners' activities and contributions more effectively both at small group and whole class levels. The design therefore aims to support peer collaboration and interaction.

The Tangram Tabletop System, or "TanTab," (Fig. 2), bridges between fully intuitive physical manipulations of tangram puzzle pieces and explicit control of the geometric

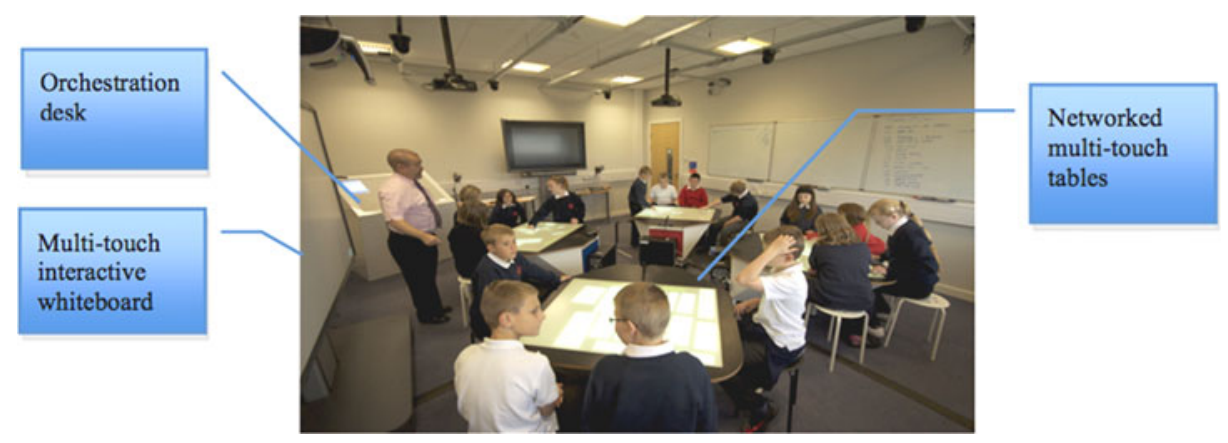

Fig. 1 The SynergyNet configuration 
Fig. 2 The TanTab system configuration

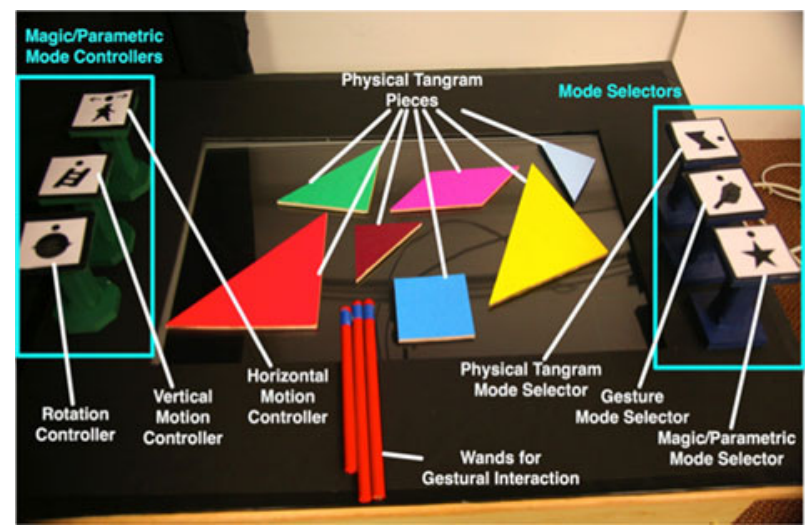

parameters that underlie the manipulation. In TanTab, children can pass gradually through three modes, from direct manipulation of physical geometric objects (i.e. tangram pieces) to direct manipulation with virtual objects. The system is comprised of a downward-facing camera that captures and tracks physical objects and hand/finger/wand gestures performed on a horizontal 30" LCD display embedded in a wooden frame. In physical mode, the physical tangrams are placed on the table; the system tracks objects, and presents their graphical shadows on the tabletop. By placing a 'gesture tile' on the table, the physical tangrams may be removed, and their graphical shadows become solid graphical objects that may be manipulated by multi-touch interaction on the tabletop (gestural mode). The child may translate a tangram piece using single wand touch and drag, or rotate the piece using two-wand interaction. Thus the child has to 'specify' the kind of operation to perform while the exact degree of movement remains intuitive and implicit. Replacing the gesture tile with a 'magic' or 'parametric tile' puts TanTab into parametric mode. The graphical objects then have to be manipulated using 'magic controllers' (rotation, horizontal translation, and vertical translation) placed on the table. The child is able to 'magically' manipulate the corresponding parameters of the selected graphical tangram piece (selection by finger or wand pointing) by rotating the controller on the tabletop, thus specifying both kind and degree of geometric operation. Placing a different control tile on the tabletop hence enables a child to move to physical manipulative, gestural, or magic/parametric modes.

The SMART ${ }^{\mathrm{TM}}$ Table is a bottom-up projection (beamer) system designed for PreKGrade 2 students (ages 4-9 in the US), which implies that it is targeted toward a very specific population with limited, though, consistent, capabilities. Evans et al. (2011b) have used the SMART ${ }^{\text {TM }}$ Table system with both off-the-shelf and custom-built applications for mathematics learning (Fig. 3). Initial research used physical manipulatives of plastic tangrams to compare to virtual manipulatives using pre-existing applications on the multitouch, multi-user SMART ${ }^{\mathrm{TM}}$ Table, utilizing three students and one instructor. The off-theshelf software application contained several features that caused unwanted behaviors, e.g., pieces could be randomly placed within the puzzle causing a mechanism to automatically position, rotate, and lock pieces within the puzzle. This caused students to rely more on the mechanism than on reasoning and collaboration. Consequently, investigators implemented a new application with the intent of making it easier to observe the behaviors and interactions of the students with the multi-touch table and each other. The latest build supports three different scenarios for each puzzle: free, divided and single ownership. In the free ownership mode, learners move any of the pieces in order to complete the puzzle. In divided ownership mode, the pieces are separated into three different colors, one for each 
Fig. 3 The SMART table configuration

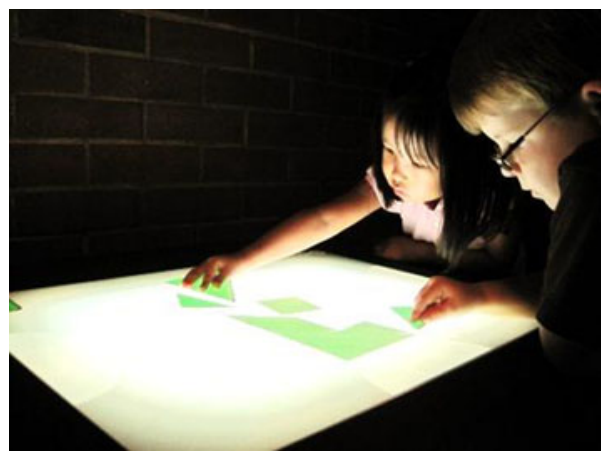

learner. In the single ownership mode, one learner can move any of the pieces while the other two learners assist in moving the piece using gestures and dialog. Each of the modes, especially single-ownership, relies on both speech and gesture in order to complete the puzzles Evans et al. (2011b).

Another tabletop (Fig. 4) allows users to build a concept map by moving pieces of paper (Do-Lenh et al. 2009). By placing two pieces of paper side by side for a second, the learners create a link between these concepts to form a map. The links are beamed from above. The learners label the links by using specific pieces of paper and they delete links with a scissorslike finger gesture. Small pieces of paper are less tangible than what is usually referred to as a "tangible" object but are nonetheless tangible, easy to hold, rotate, move and fold. The authors compared teams of 3 students using this tabletop versus teams using a standard laptop with as single mouse. The task was to build a concept map from a text on neuronal transmission. The latter groups obtained higher pre-post learning gains: apparently, the single mouse acted as a bottleneck (referred to as "single ownership" in the SMART Table project) forcing learners to negotiate verbally their choices, while the tabletop allowed parallel subtasks. We come back later on the need to design for interdependence.

The Tinker environment (Fig. 5) is an augmented-reality simulation for training logistics assistants (Jermann et al. 2008; Zufferey et al. 2009). The tabletop integrates two interfaces. A group of apprentices builds a warehouse layout by placing tangible shelves on the table. The system displays information such as the critical distance between shelves or the position of products depending on their sales. Empirical studies revealed that students were faster and learned more with the tangible than on the same activity on a multi-touch

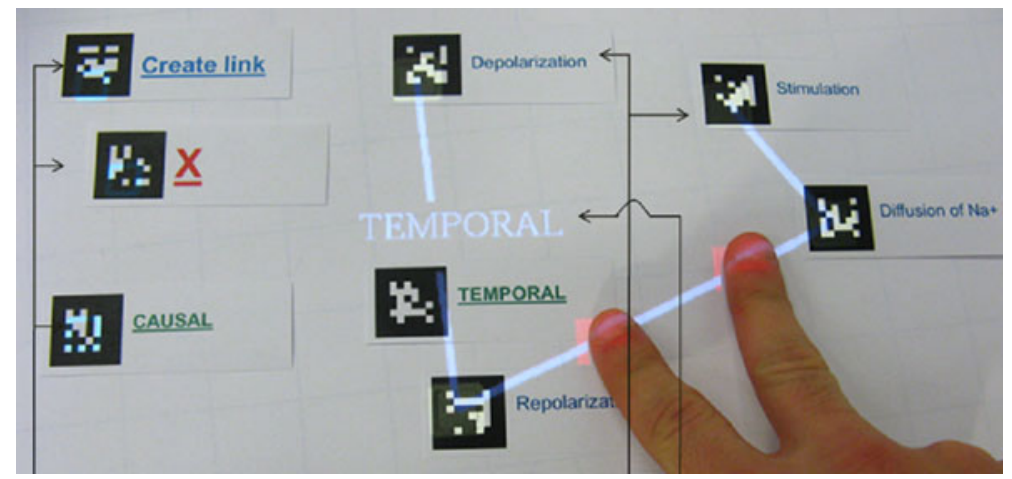

Fig. 4 Building a concept map with small paper notes 


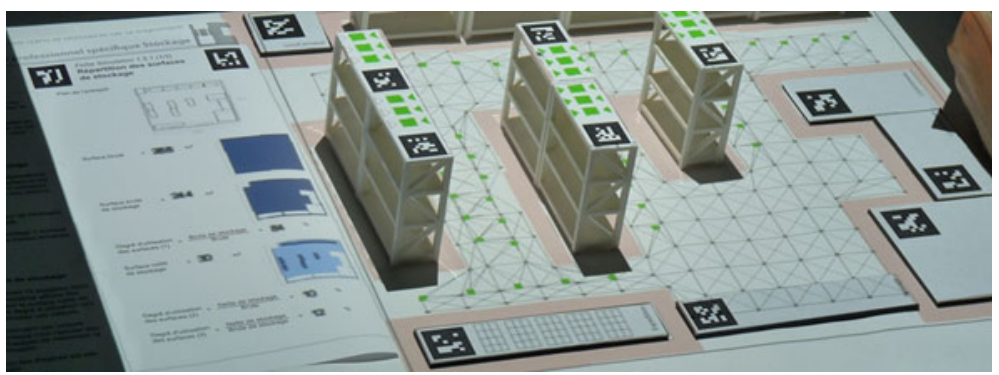

Fig. 5 Tinker environment: the tangible interface (shelves) and the paper sheets

tabletop (Lucchi et al. 2010; Schneider et al. 2010). The apprentices can start a simulation: the system beams the movements of forklifts that move boxes from the shelves to the trucks and vice-versa. The second part of the interface is made of paper sheets that learners place around the simulation area. Paper sheets are used as input device to set up the simulation parameters (e.g. the type of forklift to be used in the simulation) and as output device (the system beams results about the warehouse performance such as the average time to move a box from a shelf to a truck). Students copy this information with a pen on the sheet and use these records for instance when asked to compare their layouts on the classroom blackboard.

The same lamp is used for helping future carpenters to acquire complex 3D reasoning skills (Cuendet et al. 2011). They manipulate physical wooden blocks while the system produces the 3 orthogonal views they have to draw. Students use small cards to tune options, for instance to display the construction lines that connect the views (Fig. 6).

The DigiTile Project (Fig. 7) is a construction kit for children to explore and learn relationships between mathematics and art (Rick and Rogers 2008). Researchers conducted user studies with dyads of children, aged 9-11 years. They placed participants in two treatment groups (a split palette condition, where children had to share colored shapes; and, a shared palette condition, where each child had a full colored shape set), and one control group.

Researchers instructed the children to complete three tasks of increasing difficulty. Task 1 was to create a half-red, half-yellow pattern as depicted in a printed out reference. Task 2

Fig. 6 A tabletop for 3D geometry

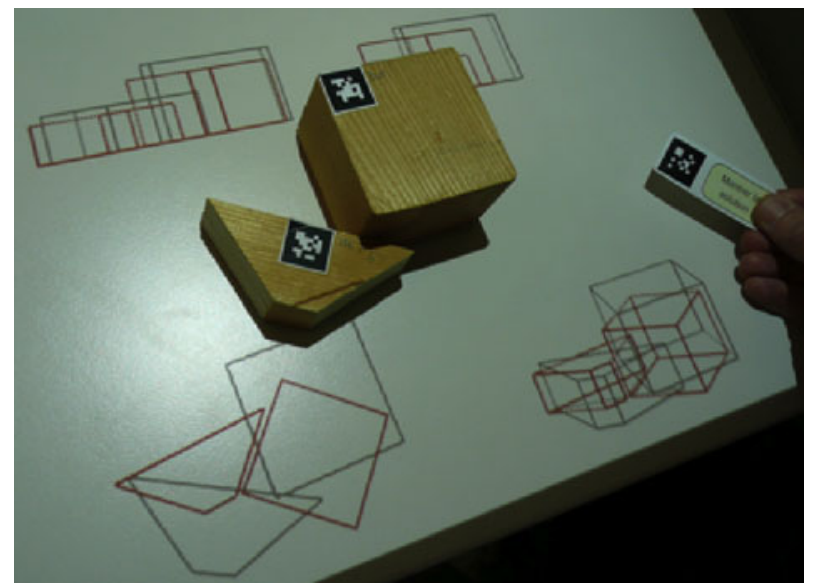


Fig. 7 The DigiTile configuration

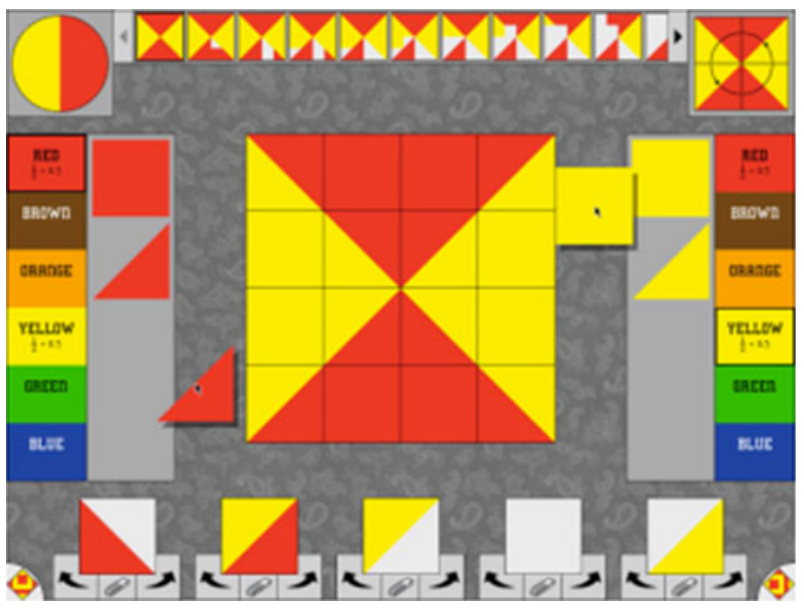

was to create a 4-by-4 tile that was equally three-eights orange and three-eights brown, the remaining areas free to be left unfilled. Task 3 was to create a 5-by-5 tile one-tenth red, four-tenths green, three-tenths yellow, and two-tenths blue. Using a pre-/post-test design, results from a one-way independent ANCOVA indicated that fraction knowledge increased as a result of the experimental treatments, a significant main effect showing for the experimental group $(\mathrm{F}(3,15)=3.45, p<.05)$. Though researchers note the limitations to the study (participants were not randomly assigned, time allotted for the task [30 min] was brief, issues with alignment of camera when table bumped by students), they were encouraged by these preliminary results for the potential of interactive tabletops to facilitate collaborative learning (Rick et al. 2011).

ArgueTable (Fig. 8) supports two learners in their argumentation during collaborative knowledge construction (Streng et al. 2011, in press). Learners can create representations for their arguments by dragging virtual notes from a stack. According to Toulmin's (1958) argument scheme, each argument note consists of three text areas: claim, grounds and qualification. Learners enter keywords to the text areas using handwriting recognition. Inactive argument notes can be minimized, as space is limited on the tabletop display. Once argument notes are built for pro and con arguments, they can be spatially arranged and connected to each other. That way, argument sequences can be built, following Leitão's argument sequence model (Leitão 2000). Pro and con arguments have connectors that are

Fig. 8 The ArgueTable

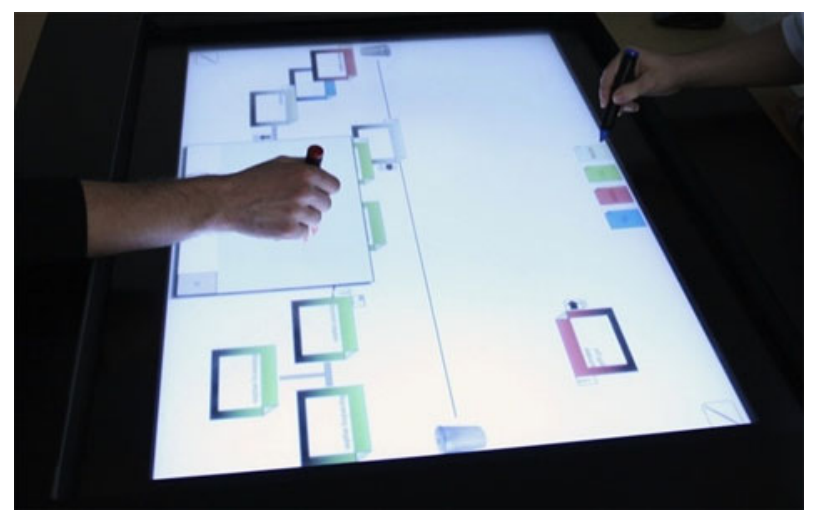


displayed as complementing puzzle pieces to illustrate that pro arguments should be attacked by con arguments and vice versa.

The Digital Mysteries Project (Kharrufa et al. 2010a, b), based on the mysteries paperbased learning counterpart, is positioned as capturing a design methodology that prioritizes the externalization of thinking and high-order thinking skills. The Digital Mysteries design, development, and evaluation activities were conducted with the Promethean Activboard, comprised of solid upward projection system and pen-based input devices. Over the course of three iterations, working with students (aged 11-14) in triads and progressing from offthe-shelf paper versions to interactive tabletop-specific digital artifacts, four features resulted that are supported by the direct-input surfaces (Kharrufa et al. 2010a, p.199-200): 1) structuring the learning process with timely, reflective feedback; 2) providing provisioning tools to make thinking visible; 3) switching between single and parallel input to support collaboration and increased awareness of peer participation; and 4) allowing for unobstructed audio and visual cues as well as free movement by participants. A primarily qualitative, multimodal analysis of group interaction over 22 videotaped sessions provided encouragement to researchers that the designed affordances described above had detectable positive influences on externalization of thinking and higher-order thinking (metacognition). In terms of externalization, researchers surmise that the Digital Mysteries tabletop application containing multimedia elements and element-linking features provided a snapshot for making group cognition visible. An analysis of discourse revealed that students appropriated the structuring and feedback features to alter approaches to sequencing explanations (from branched to linear). Though one should take these results with caution, they do demonstrate design and learning opportunities afforded by interactive, direct-input tabletops.

\section{The educational flavor of tabletops}

As mentioned in the introduction, technologies have no intrinsic pedagogical effects. Tabletop environments are not intrinsically constructivist for instance: they could be used for presenting multiple-choice questions or for reading textbooks for rote recall. Almost any educational software can actually be run on these horizontal computers: frame-based learning, drill and practice, simulation, modeling, microworlds, hypertext materials, etc. However, if one focuses on the deep differences between desktops/laptops and tabletops, the latter implicitly convey a pedagogical flavor that can be captured by the following points presented below:

1. Tabletops are designed for co-location. Even if the CSCL field was initiated by Roschelle's work on two students facing a single computer (1992), most CSCL environments since have focused on online interactions. Environments for co-present collaboration have continued to exist through single-display groupware (Stewart et al. 1998), multiple-display groupware (Koschmann 1999), multi-input devices (Inkpen et al. 1999), the "one mouse per child" approaches (Nussbaum et al. 2009) as well as integrated macro-scripts (Dillenbourg and Hong 2008). Tabletops are aligned to this evolution. The impact of co-presence is not only that learners see each other, touch each other and exchange objects, but also that the organization of the physical space becomes a key issue while the placement of laptops in a classroom has rarely been addressed in research on virtual learning environments.

2. Tabletops are designed for multiple users. Fundamentally, a table is a social place while a desk is a personal space: the same holds for digital tabletops and digital desktops. 
Even if laptops can be used collaboratively, they have been designed as "personal computers". Though individuals can certainly use tabletops, their input technology and dimensions have been specified for multiple users. Let us stress that the meaning 'multi-users' is not the same in tabletops and in virtual learning environments: each user has an identity in the latter (login) but not often in the former. Tabletops are intrinsically "interpersonal computers" (Kaplan et al. 2008).

3. Tabletops are designed for hands-on activities. The dominant model of interaction on a tabletop is to solve problems by moving virtual or physical objects on the surface with ones hands or prosthetic (e.g., pen, stylus, or wand). Thereby, tabletops seem to be more suited for tasks in which concrete manipulations are important for solving the problem, which explains why many applications primarily serve children and novice learners.

4. Tables are designed for multiple modes of communication. The affordances of the above three lead to multiple modes of communication — talk, gesture, gaze, action, and posture that allow for richer discourse available for teaching and learning, research and analysis (Evans et al. 2009a, b; 2011b).

These points, when made explicit and prioritized, reveal a socio-constructivist flavor: tabletops favor hands-on problem solving activities conducted in teams of co-located peers. Their flavor is also more physical than usual CSCL research: the physical manipulation of objects and the organization of the physical space around the tabletop are new issues in our field. We use the term "flavor" to indicate that we do not claim that any tabletop activity is socio-constructivist but that tabletops afford socio-constructivist approaches.

This physicality justifies the need to investigate distinctively interactive tabletops and electronic whiteboards that are spreading quickly in schools and informal learning environments. Technologically speaking, one could argue that an electronic whiteboard is nothing less than a vertical tabletop. However, whiteboards support educational activities that do not match the features and the educational flavor of tabletops. Designed for enhancing teacher lectures, as blackboards or beamers, they are mostly teaching tools. Therefore we have limited the scope of this paper to tabletop environments. Our position can be summarized as follows:

Desk(top)s are personal, table(top)s are social, and (digital) whiteboards are public.

\section{Circles of interactions}

To analyze the affordances of tabletops, we discriminate four circles of interaction. Learning may result from interactions at any of these levels.

Circle 1. User-system interactions: How does a tabletop potentially change the way students learn individually? Elementary schools have a long tradition of children manipulating concrete objects for learning, going back to Froebel. How cognitively different is it to move concrete objects versus virtual objects (Evans and Wilkins 2011)? Does it really matter to move them with fingers versus with a mouse? How different is it to interact with a horizontal or a vertical display? Do we detect different types of communicative patterns as we move between physical and virtual objects (Evans et al. 2011b)?

Circle 2. Social interactions: How does a tabletop environment potentially influence the interactions among the students around the table? Do students talk more to each other because the display is horizontal? Do they give objects to each other (Evans et al. 2009b)? 
Circle 3. Classroom orchestration: How does a tabletop influence the way a teacher orchestrates multiple learning activities in the class? Does the environment include secondary displays for reflection or control? How many tabletops can be used in one classroom and should they be connected? Can the teacher reuse the tabletop productions in her or his debriefing lecture? Do students watch over the shoulders of students working on other tables?

Circle 4. Institutional context. Are tabletop environments better suited for specific contexts (formal/informal learning), ages and learning cultures? Do they expand educational activities to places that were not previously considered as principal learning places, e.g., museums, zoos, science centers, etc.?

While circle 1, 2 and 4 have often been studied in CSCL, the investigation of circle 3 has become more important with the development of tabletop environments and related novel interfaces (ambient displays, tablet and mobile devices, etc.). For Circle 1, the constraints that have been investigated concern the individual's cognitive load, pre-requisite knowledge, experience, motivation, engagement, etc. For Circle 2, the explored constraints are, for instance, the team's need to build enough shared understanding to carry out the task at hand. For Circle 3, teachers have to cope with many constraints: curriculum relevance, time budget, time segmentation, physical space, discipline, security and many others (Dillenbourg and Jermann 2010a). Understanding the relationship between CSCL design and the management of these constraints is what we refer to as "usability at the classroom level" (Dillenbourg et al. 2011). Classroom orchestration refers to the real time management by a teacher of multiple learning activities within a multi-constrained environment. Classroom management is as old as schools, but it became salient in CSCL when scenarios (or scripts) began integrating individual, collaborative and class activities (e.g. readings, lectures).

\section{Circle 1: Learner-tabletop interactions}

Some of the issues listed below are general HCI issues that concern any application running on a tabletop (games, meetings, planning sessions), while others are specific to learning. We do not restrict ourselves to the latter since the general HCI issues are also relevant for choosing learning tasks that can benefit from tabletop activities.

1. Movements. Most tabletop environments support multi-finger gestures that are especially useful to move, rescale and rotate an object. These gestures are often described as being intuitive or 'natural' but they also have drawbacks: finger-based actions are less precise than those operated with a mouse cursor (see next point on occlusions) and do not include the various possibilities offered by mouse buttons (e.g. right click, drag-and-drop, etc.). The ratio between these gains and losses must be assessed on a case-by-case basis to estimate the relevance of a tabletop interface for a specific learning task. Globally stated, the tasks or domains for which tabletops are relevant are tasks that do not require setting up a large number of parameters or a large set of small objects. Tabletops are suited for tasks that require the spatial organization of objects, fluid manipulation and a perception of the whole scene.

2. Objects. Some tabletops use digital objects (images, icons), some use tangible objects. This raises HCI questions such as the fact that the speed of manipulating tangible objects is faster than for virtual counterparts (Lucchi et al. 2010). The counterpart educational question is: when is there an added value of manipulating physical versus virtual objects? 
a. How much are understanding and memory embodied into tactile and kinesthetic perception of objects? To compensate for the potential loss of tactile and kinesthetic feedback, explicit information may need to be provided. For example, when manipulating geometric shapes, information about size, shape, and comparative location could be provided. Moreover, hints demonstrating partial solutions provide a similar supportive function (Evans, et al. 2009a). This is of course not a new question.

b. What is the degree of abstraction of these objects? How figurative should they be? For instance, in the Tinker environment, the small shelves do not have a direct physical mapping with the actual shelves that apprentices see in their workplace; they are rather $3 \mathrm{D}$ icons with a conceptual mapping to the reality. As learning often requires moving up from concrete to more abstract representations, how should this transition be implemented? In Tinker for instance, at some point, physical objects are replaced by digital images, with a different scale. This design of tangibles is especially important when considering young children, as some educators are concerned that limitations to $2 \mathrm{D}$ interaction in a virtual environment could impede critical cognitive development to 3D orientation, manipulation, and movement (Olkun 2003).

c. What is the information provided by a $3 \mathrm{D}$ object compared to a $2 \mathrm{D}$ object? In the Tinker environment, the tangible shelves provide students (who usually face problems to draw plans at different scales) with a very intuitive perception of the ratio between the shelve height and the alley breadth. The objects per se embed a scaffold.

3. Problem states. Tabletops are relevant for problem solving if the state of the problem can be represented by the position of objects (location+orientation). If representing the problem state requires, for instance, multiple layers, current tabletops are less relevant than a multiple windows system (although auxiliary displays can be used). Tangibles interfaces do not allow any "UNDO"; actions have to be undone manually, while multi-touch tables can return to previous states. This confirms that tabletops are relevant for rather simple tasks, where the ease of manipulation is more important than the management of multiple problem solving paths.

4. Feedback modality. Tabletop environments mostly provide feedback in a visual way. They can be enriched with audio feedback but this raises problems at circle 3 (noise in the classroom). The use of tangibles also provides tactile feedback (e.g. the user feels that object A touches object B). New techniques provide tactile feedback with vibrating surfaces that create an illusion of friction (Winfield et al. 2007). Other tabletop prototypes (Pangaro et al. 2002) explore the possibility that objects move by themselves, which would be relevant for simulations.

5. Feedback timing. Two levels of system feedback must be dissociated in any learning technology: the non-didactic response to user actions (e.g., displaying the result of the user actions in the simulation) and the didactic evaluation of users' answers. While immediate non-didactic feedback make tabletops "engaging technologies" (Rogers 2006), the didactic feedback should not always be immediate. The choices between immediate feedback, which creates associations but may prevent reflection, and delayed feedback reflect theoretical choices. Teams engaged in playful manipulations may not spontaneously take the time and the distance necessary for reflection. Therefore, in Tinker, we added a "simulation lock". Students are not allowed to run the simulation in a pure trial-and-error mode. Before, the teacher has to come to their table, to ask them to predict the result of the simulation (e.g. increase or decrease of 
goods movements) and only then does the teacher place the key on the table that allows the simulation to run. (See circle 3 about the teacher's role).

6. Heads-in/Heads-on. This continues the previous point. While objects allow learners to directly do what they want to do (instead, for instance, of verbalizing it), there is a need for activities where they take more distance to predict, analyze, compare or reflect. Therefore, some scholars developed an auxiliary display, often vertical, where learners can see a different representation of what they have done. The Tinker environment use paper sheets for reflection. Other systems use personal displays such as PDAs or laptops (Africano et al. 2004). Empirical work has shown that virtual manipulatives can be designed so as to emphasize differently, depending on learning goals, a heads-in vs. heads-on posture (Evans and Wilkins 2011). In other cases, the reflective activities are not included in the tabletop activities but left to the teacher for class wide activities (circle 3 )

7. Occlusions and shadow. When projections are made from above the table, several HCI issues emerge. When users hands hide the objects to be recognized (e.g., the tags can be hidden by the thumb of the user who moves the object), the object disappears for the system. A scene is more stable if the designer makes the hypothesis that a short disappearance of the tag is an occlusion rather removing the object. How redundant should the object-recognition algorithm be to cope with partial occlusion (e.g., pasting several tags)? Even if visible tags are not especially beautiful, their advantage is that users are aware of their position and hence take care naturally about occlusions. When the input is made of physical objects, these objects create shadows that are detrimental to the image analysis by the camera. If the beamer is placed above the centre of the scene, these shadows can be quite important at the periphery of the display. Actually, shadows can be used as part of the environmental variables such as what was used in URP: the Luminous tangible table from the MIT Media lab (Underkoffler and Ishii 1999). This issue — as well as those that follow — are not specific to learning tasks but to usability, which is a condition for learning.

8. Tags legibility: Most tags are visible by both the system and the user but can only be interpreted by the system. When this disequilibrium raises a problem for the application, there are two solutions. The first one is to make the tag invisible to the user, e.g., by using infrared ink and infrared cameras. The second solution is to design tags that are human readable but nonetheless geometrically encoded as other 2D tags such as in Fig. 9. The TanTab system, detailed above, also adopted a scheme whereby tags were both machine- and human-readable.

Fig. 9 Fiducial marker recognizable by the system and the user (Costanza and Huang 2009)

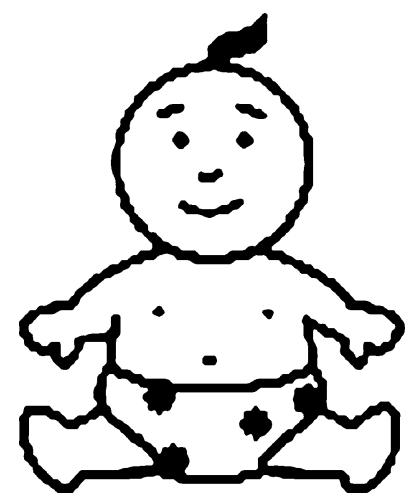


9. Persistence of objects. Do the objects exist outside the display area? Virtual objects disappear outside the display while physical objects (tangibles, tools, paper sheets) remain visible even when placed on the non-interactive part of the tabletop that sometimes surrounds the interactive area. Persistent objects enlarge the working space: The set of available objects placed around the interaction space provides users with an overview of possible actions. In the Tinker environment, paper sheets also show continuously which menus and options are available and can be placed in the interactive space. Persistence is a powerful feature of tangible objects. Users are not compelled to learn what is available in menus and toolboxes; s/he sees them all. This could prove a fruitful area of research and development as many systems now available default to adopt the entire surface as interface. The border, non-interactive, areas associated with tabletops could serve instructionally beneficial affordances overlooked to maximize the interactivity of available surface area.

10. Input-output coupling. While traditional interfaces dissociate the input surface (the mouse on a horizontal surface) and the output surface (the vertical display), these two areas are merged on tabletops: they are not only in the same horizontal plan (avoiding the translation between planes) but they do also overlap. Tabletops therefore are more relevant for tasks that require fast movements to a target or that require a tight coupling between input and output. However, interfaces that dissociate the input and output spaces offer the advantage of supporting "relative" movements: the absolute position of the mouse on a desk does not correspond to the absolute position of the cursor on the screen, the mouse movements correspond to the cursor movements. When a tabletop supports physical objects, the input/output coupling can only be absolute: each point of the input space is coupled with a point in the output space. This restricts the application of tangibles in tabletops to the workable surface. Pedagogically, an issue is how important the absolute or relative mapping of movements is critical to learning. For young or novice learners, absoluteness may be important as they acquire new knowledge or skills. Particularly for younger learners, there may be developmental reasons for preferring absolute mapping.

11. Comfort. Some tabletops are designed for users who sit around it, some for standing users. This is often related to the technology: when the display is beamed from below, the space under the table, where the beamer and mirrors are placed, must be protected but this prevents students to sit comfortably. While this issue is not salient in demos and in public spaces (exhibitions or cafes), it is a concern when considering longer activities. Moreover, the height of the table, designed for children aged 4-9, deters extended comfortable interaction for adults. The ergonomics of these design choices play a role in how and how long efforts are extended, and by whom.

12. Dimensions. Most tabletop activities occur on a 2D surface; only a few exceptions use $3 \mathrm{D}$ such as the interactive sandbox designed by Piper et al. (2002). Current tabletop technologies are still designed neither for perceiving the vertical position of objects (although all technology is available) as well as for coping with the superposition of objects, i.e. with (partly) hidden objects. One stopgap solution, for example, when one is working with manipulatives, is to create objects that shift opacity when juxtaposed. A case in point is the manipulatives created for the SMART Table by Evans et al. (2011a), who imposed a glass-like texture to objects so that when one object was slid over another, the user could detect that one piece was superimposed over another. 
Circle 2: Social interactions around tabletops

The foundational principle of CSCL is to shape the interactions among students. Here are some examples of how tabletops achieve this.

13. Multi-users. By their shape and size, tabletops are intrinsically designed for multiple users: they are "interpersonal computers" (Kaplan et al. 2008), as opposite, to the concept of "personal computers". However, while most CSCL tools identify every user by an individual login or an individual input device (Inkpen et al. 1999), this is rarely the case in tabletops. The Tinker environment, for instance, knows where the shelves are placed but ignores how many hands are moving these shelves. In multi-touch tabletops, if two fingers are placed on the table, how does the system know if they belong to one person performing a two-finger action or to two persons each performing a one-finger action? The DiamondTouch table (Dietz and Leigh 2001) indentifies users by asking them to stand on electrical carpets and Watanabe et al. (2008) does this by placing RFID readers in the gloves users wear to grasp objects. Identifying users is not always necessary in CSCL, but, if it is, tabletops may not be the best approach.

14. Interdependence. Long before the development of CSCL, interdependence among students was emphasized as a key principle to design collaborative learning tasks (Slavin 1983; Suthers 2006). The experiment of Do-Lenh et al., reported above, illustrated this point. The computational mechanisms within multi-touch systems can be re-analyzed in that way. Some actions require one finger (moving an object) while other actions require two fingers (enlarging an object). Other actions could require three or four fingers. Creating tabletop activities requires carefully designing the degree of interdependence that the software should support. Evans et al. (2009b) imposed interdependence on PreK students while working with tangram pieces. In what was labeled "single" mode, only one student among three was allowed to touch the virtual tangram pieces while two peers verbally directed action to solve the puzzle. In "divided" mode, each user could touch their colored piece when solving the puzzle. The teacher had to control if users followed these modes.

15. Shared workspace: Quasi-WYSIWIS. A basic design principle of CSCW is "what you see is what I see" (WYSIWIS; Stefik et al. 1987). Tabletops are WYSIWIS: not only learners see the same things, but they do also see what others do in the shared space (see the point below on 'public gestures') and what others pay attention to (see the point below on 'attention awareness'). We nonetheless refer to tabletops as "quasi_WYSIWIS" environments because users don't have the same viewpoint (see the point below on "display orientation"). Actually, CSCW scholars found that the WYSYWIS principle cannot be applied in a systematic way. When the task is too complex or when the number of users is too high, the so-called "relaxed-WYSIWIS" environments (Greenberg et al. 1996) allow users to work on different subspaces of the workspace. In Caretta (Sugimoto et al. 2004), users can try a solution on their private PDA before proposing it to the group. Large tabletops also support relaxedWYSIWIS principle since learners can work on a subset of the task: personal subspaces emerge on the surface (see the point on 'territoriality').

16. Display orientation. In single display groupware, all users have the same viewpoint. In contrast, the students around a tabletop have different viewpoints. Should the software enable participants at different table locations to have the same viewpoint by duplicating or rotating images (Africano et al. 2004, in DiamonSpin, Shen et al. 2004a, b)? Should, instead, the environment exploit pedagogically the difference of 
viewpoints as in the experiments on socio-cognitive conflict (Doise and Mugny 1984)? Some tasks are intractable from the wrong viewpoint (e.g. reading small characters) while other ones actually benefit from multiple viewpoints (e.g. 2D layouts). If the system duplicates the display to provide identical viewpoints to each user, it decreases proportionally the size of what can be shown to each student. When children work around a physical table, they constantly re-orient pieces to gain perspective or share with others for assistance with little effort. Is it desirable to replace these movements by software features or are they part of learning?

17. Public gestures. An interesting feature of tabletops is that all learners perceive their peers' gestures. A learner does not only see when his or her partner has finished to move an object, but (s)he sees the gesture from its outset. We often witnessed that a learner interrupts the gesture of another learner while he is accomplishing it, making collaboration very informal (Evans et al. 2011a, b).

18. Attention awareness (or gaze awareness). While CSCW research devoted many efforts to provide users with the awareness of what the other users do/look at, the face-to-face situation provides naturally this awareness. Simply, learners see what peers pay attention to, without overload. This point combines the previous one: since gestures map directly to intentionality, the meaning of the act can be combined with other inputs, including speech, gaze, and posture. These episodes of "coreference" (McNeill 2006) provide an extremely rich set of data available to peers and analysts.

19. Group working memory. When students manipulate digital or physical objects on the tabletop, this set of objects represents the current state of the problem. Because they are WYSIWIS, they can be used as a resource to grounding utterances (Dillenbourg and Traum 2006). The tabletop provides users with a shared representation of the state of the problem. The relevance of the objects and structure of objects to represent the solution states is a key design issue.

20. Territoriality. Do students have access to the whole environment (given the size of the tabletop and the length of their arms) or do they only manipulate objects in their vicinity? Do students move around the table? Do virtual/physical objects belong to some users? The ReflectTable (Bachour et al. 2010) is not exactly a tabletop but the notion of territoriality is strong: the table has microphones that detects who is speaking and the LEDs embedded in the table in front of him progressively turn on to reflect his speaking time. If he speaks profusely, his LED-revealed territory will invade the space in front of other learners. Territoriality can be designed to differentiate the roles within CSCL scripts (e.g. table location gives access to a certain role) and rotating roles becomes a simply physical rotation around the table.

21. Roles. Many CSCL scripts assign different roles to students, either generic roles such a 'proposer', 'criticizer', 'summarizer', etc. (Schellens et al. 2005) or domain-specific roles such as Vygotsky, Piaget and Skinner. In the Tinker environment, roles are translated into the use of special cards that are recognized and give them specific rights. If the teacher wants to transfer a role to the students, (s)he simply gives the card to the students for a certain time. For the TanTab system, the proposal is for users to wear identifying tags or gloves that can be detected by the computer vision.

\section{Circle 3: Classroom orchestration}

Most existing tabletops are too expensive and too big for installing them in a way that is comparable to existing classroom arrangements, for instance, 5 tabletops for 20-25 students. 
More frequently, a single tabletop is placed in a dedicated room, or placed in the corner of a classroom (much like a sand or water table in early childhood education settings), where students work in small groups. This was the case for the first version of Tinker, a large table placed in the school basement. This implied that teachers had to manage two subsets of students in parallel. In the next version of Tinker, a smaller lamp has been placed on the students' desks, allowing teachers to handle the whole class at once. However, installing four lamps in one classroom raises several issues that concern classroom orchestration.

22. Workflow integration. How is the tabletop activity integrated into the sequence of learning activities? What comes before: introductory lectures, readings, a walkthrough by the teacher, etc.? What comes after: a teacher debriefing, students have to write a report, a selected group has to replay the episode for the entire class? In the Tinker experience, the crux of learning was when the teacher asks every team to report their solution on the whiteboard and ask them to explain the differences in performance. Which traces and objects are produced through tabletop activities: can learners and teachers access the solutions constructed on the tabletop once they do not have any more access to the table? We are not talking here about complex log files or finegrained traces but rather about saving the students' productions.

23. Line of sight. A good teacher permanently monitors the activity of every student in his classroom, combining a regular visual scan and peripheral vision (as well as audition). Tabletops enable this rapid visual scan if the objects placed on the table are visible within a 5-meter radius. Of course, the design of the device should not break this visibility. For instance, Fig. 10 shows two designs of the Tinker lamp: the left one is nicer for team work (circle 2), since the opaque back creates some team intimacy, while the right one, with a transparent back, is better for orchestration (circle 3) since the teachers perceives all teams at a glance.

24. Light management. At the current stage of technological development, the amount of light remains an issue for many tabletops that require a level of darkness that is not suitable for classroom use. Moreover, tabletops that use cameras for input rely on thresholds that are sensitive to light: a sudden ray of sunshine on the classroom windows may skew the recognition of objects. This fragility may make classroom orchestration very difficult. Orchestration is easier with robust technologies: for instance tags recognition is less sensitive to light variations than finger tracking.

25. Over-hearing and Over-seeing: If several tabletops are placed in the same room, students accidentally or voluntarily hear/see what the learners at the next table are

Fig. 10 Different form factors for the Tinker lamp
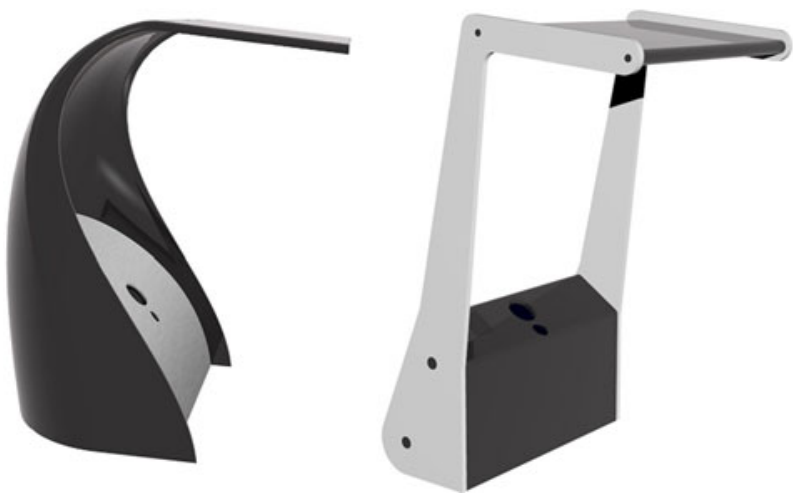
doing. In a productive fashion, this is referred to as articulation work (Schmidt and Bannon 1992). Should the teacher assign different problems to groups for avoiding plagiarism or conversely give them the same problem and foster inter-team collaboration or competition? Some designs actually foster over-seeing by using auxiliary displays: a team is working of the tabletop and his work is displayed (e.g. via a beamer) to the rest of the class to which the teacher assigns another task.

26. Generalizability. Tabletops are not mobile or, if they are, can be quite heavy and cumbersome in an all-enclosed configuration. Therefore, once they are installed in a classroom, they should support learning across different domains: the price cannot be justified if they are only used a few hours per week. What is the generalizability of tabletops' applications? When users manipulate tangible objects, the application is restricted to the domains for which these objects are relevant. This is a main shortcoming for tangibles in education. For instance, Tinker shelves are bound to teaching logistics. Of course, one can use generic tangibles, such as Lego blocks. The goal of tangibles is nonetheless to use task specific objects.

27. Networking. Installing several tabletops would partition the class into subspaces. These subspaces can be networked to create pedagogical scenarios. In ePRO (Sugimoto 2009), the city created by students on a table does produces pollution that can be transported by the wind (simulated by the network) to the city constructed on another table. In Tinker, the trucks that leave warehouse $\mathrm{X}$ could deliver goods to the warehouse $\mathrm{Y}$ and illustrate how a delay in a single production unit affects the whole production chain. What is interesting here is the fact that these inter-table workflows correspond to the contents to be learned. In the SynergyNet system above (Fig. 1), a set of tables is networked to a teacher's orchestration platform, which can be used as a pedagogical or monitoring tool.

28. Diagnosis and Assessment. Given the tracking and recording capabilities of the interactive surfaces, the potential for improved diagnosis, assessment, and evaluation is encouraging. An example is the TanTab system, which combines computer vision and machine learning to track and learn the inputs and actions of learners (Fig. 2). The recordings from sessions at the table could be used for concurrent, machine-based assessment or replayed at a later time for human review and assessment. One scenario, taking the early childhood mathematics scenario from earlier, is that the system could diagnose levels of understanding and present appropriate activities or support to learners based on puzzle completion parameters. In essence, the system combines interactive surfaces with intelligent tutoring system capabilities.

29. Ecology of devices \& interoperability. The current speed at which multi-touch, multiuser technologies are being produced for mass consumption, and the relative changes in policy and perceptions of using personal devices in the classroom, pose opportunities and challenges in terms of managing, maintaining, and orchestrating a classroom proposed as an ecology of devices. From a technical standpoint, the issue of interoperability of personal desktops, small group tabletops, and class whiteboards is an impeding reality and area calling for further research. From the pedagogical viewpoint, these ecosystems require new orchestration skills from teachers.

\section{Circle 4: Contexts}

Tabletops are used in formal and informal education as well as in a variety of leisure and exhibition situations that are not educational but can nonetheless inspire educators and 
instructional designers. As mentioned earlier, they are used with groups of different ages, from kindergarten up to senior citizens.

30. Formal versus informal. One feature of tabletops that make tabletops particularly relevant for informal learning contexts is that they do not have an instructional lookand-feel; they look more like a playful environment than like an e-learning material. Standing-when-learning is, however, also a possible problem with tabletops, since it does not support long tasks, although it has the advantage to make it so different from school chairs.

31. Learning, work and play. The tabletop is a ubiquitous feature of learning and work environments. The software that accompanies an interactive tabletop could be augmented to adapt to varying scenarios the emphasize learning, work, and play. Nowadays, play is seen as an integral part of motivating learning and work.

32. Culture. An example of cultural issue raised by tabletops has been cited before. We mentioned 'public gestures' as an advantage of tabletops, because it allows a smooth coordination among actors. Conversely, tabletops also make publicly visible the errors made by user. Making a public mistake is a culture-sensitive issue and it is hence not surprising that what emerged in Japan was the Caretta tabletop (Sugimoto et al. 2004), which allows pretesting a solution in one's own private space (a PDA) before applying it to the tabletop. The adoption of the Tinker tangibles by manual workers can partly be explained by a cultural fit. One design principle for tangibles could be to reproduce the objects that learners would consider as specific to their culture.

33. Knowledge domains and disciplines. Interactive tabletops may provide a platform, given appropriate pedagogy and accompanying software, to present knowledge domains and disciplines in a more integrative fashion. As pedagogy moves to break down barriers between knowledge domains and disciplines, educational software designers carefully consider interdependence, multiple-perspectives, and coconstruction. One example, in the United States, is the current emphasis on science, technology, engineering, and mathematics, commonly referred to as STEM. Pedagogical software such as epistemic games (Shaffer 2005), represent a new development in intertwining not only disciplines, but cultures as well.

\section{Conclusions}

In the Introduction, we stressed the fact that tabletops are intrinsically neither good nor bad for learning. To understand when they are relevant, one needs to consider many specific issues that we listed, i.e., to deeply analyze how the heart of tabletops-manipulating objects together - is related to learning. This is not an easy analysis that could be performed on five criteria; it is more complex. Some issues may seem more connected to HCI than to education: We would argue that tabletops require an intense dialogue between HCI and learning sciences. This list of issues is structured into four levels, but it is far from a wellstructured taxonomy. Educational tabletops are new; it will take a while to build a sound theoretical framework.

We started this paper by addressing one myth, the intrinsic educational effectiveness of media. We conclude by attacking another myth, the holy quest for 'natural' interactions, i.e., the design of computer interfaces that would be as 'natural' as the gestures we perform in everyday life. We question the assumption that tabletop interaction is a major step towards 
'natural' interfaces. Let us consider the "naturalness" of three modalities for moving an object: by moving a digital object with a mouse, by moving a virtual object with fingers (on touch-sensitive displays) and by moving a tangible object with normal gestures (as in Tinker). Most learners have used a mouse for many years: for them, moving digital objects with fingers is actually less natural than with a mouse. They are even surprised the first time they do it. Conversely, in Tinker, moving a tangible shelf on a surface is as 'natural' as moving a cup of tea on the table... but only if one forgets what the object represents: they represent shelves, and it's absolutely not natural in the real world to move a shelf with two fingers.

In a similar way, tabletops on which users can write with a pen are perceived as more natural than tabletops using a keyboard for text entries. This 'naturalness' is based on ignoring the thousands of hours of practice kids spend from kindergarten to elementary school for learning complex writing gestures. Even the simple gesture of grasping and moving an object has to be learned through years of development, as shown by Piaget. Hence, the word 'natural' should be disentangled into several dimensions: is the gesture to be learned specifically for this interface or is it supposed to have been learned before by most users; how is this gesture specific to the culture of target users; what is the directness of the interface, etc. Our message is that we should not expect great learning outcomes from tabletops simply because they are more "natural" than desktops. Instead, understanding the potential of tabletops for education requires a more detailed analysis, circle by circle, of their affordances. The 32 design issues that we described provide a first grid for the design or analysis of educational tabletops.

Acknowledgements This paper introduces a special thread of papers in $i j C S C L$ that originates from a workshop 'Tabletops for Education' organized by P. Dillenbourg and C. Shen at in the Second Alpine Rendez-Vous, in Garmish-Partenkirchen (Germany) in December 2009. This workshop was funded by STELLAR, a European Network of Excellence on Technology Enhanced Learning.

This article was supported, in part, by a National Science Foundation Grant (IIS 073615) awarded to Michael A. Evans.

\section{References}

Africano, D., Berg, S., Lindbergh, K., Lundholm, P., Nilbrink, F., \& Persson, A. (2004) Designing tangible interfaces for children's collaboration. Proceedings of CHI 2004, April 24-29, 2004, Vienna, Austria.

Arias, E., Eden, H., Fischer, G., Gorman, A., \& Scharff, E. (2000). Transcending the individual human mind: Creating shared understanding through collaborative design. ACM Transactions on Computer-Human Interaction, 7, 1.

Bachour, K., Kaplan, F., \& Dillenbourg, P. (2010). An interactive table for supporting participation balance in face-to-face collaborative learning. IEEE Transactions on Learning Technologies, 3(3), 203-213.

Blatchford, P., Kutnick, P., Baines, E., \& Galton, M. (2003). Toward a social pedagogy of classroom group work. International Journal of Educational Research, 39(1-2), 153-172. doi:10.1016/S0883-0355(03) 00078-8.

Costanza, E. \& Huang, J. (2009). Designable visual markers. Proceedings ACM CHI2009. Boston, MA, USA, April.

Cuban, L. (2003). Oversold and underused. Computers in the classroom. Cambridge: Harvard University Press.

Cuendet, S., Bonnard, Q., Kaplan, F. \& Dillenbourg, P. (2011) Paper interface design for classroom orchestration. CHI, (To appear).

Dietz, P., \& Leigh, D. (2001). DiamondTouch: A multi-user touch technology. In Proceedings of UIST'01 (pp. 219-226). New York: ACM Press. 
Dillenbourg, P. \& Hong, F. (2008). The mechanics of CSCL macro scripts. International Journal of Computer Supported Collaborative Learning, 3(1), 5-23.

Dillenbourg, P., \& Jermann, P. (2010). Technology for classroom orchestration. In M. S. Khine \& I. M. Saleh (Eds.), New science of learning: Cognition, computers and collaboration in education (pp. 525-552). Dordrecht: Springer.

Dillenbourg, P., \& Traum, D. (2006). Sharing solutions: Persistence and grounding in multi-modal collaborative problem solving. The Journal of the Learning Sciences, 15(1), 121-151.

Dillenbourg, P., Zufferey, G., Alavi, H., Jermann, P., DoLenh, S., Bonnard, Q., et al. (2011) Classroom orchestration: The third circle of usability. Proceedings of the 9th Computer-Supported Collaborative Learning Conference, Hong-Kong, (To appear).

Doise, W., \& Mugny, G. (1984). The social development of the intellect. Oxford: Pergamon.

Do-Lenh, S., Kaplan, F., \& Dillenbourg, P. (2009). Paper-based Concept Map: The Effects of Tabletop on an Expressive Collaborative Learning Task. In Proceedings of the 23rd British HCI Group Annual Conference on HCI 2009: Celebrating People and Technology (Cambridge, United Kingdom, September 01-05, 2009). British Computer Society Conference on Human-Computer Interaction. British Computer Society, Swinton, UK, 149-158.

Eden, H. (2002). Getting in on the (inter)action: Exploring affordances for collaborative learning in a context of informed participation. In Proceedings CSCL '02 (pp. 399-407). ISLS.

Eden, H., Scharff, E., \& Hornecker, E. (2002). Multilevel design and role play: Experiences in assessing support for neighborhood participation in design. In Proceedings of DIS '02 (pp. 387-392). New York: ACM Press.

Evans, M. A., \& Wilkins, J. L. M. (2011). Social interactions and instructional artifacts: Emergent sociotechnical affordances and constraints for children's geometric thinking. Journal of Educational Computing Research, 44(2), 141-171.

Evans, M. A., Ryon, E., Feenstra, A., \& McNeill, D. (2009a). Discourse coding from a multimodal approach: Distributed cognition \& geometric problem solving in young children. Paper presented at the AlpineRendezvous Workshop, November 30-December 2, 2009, Garmisch-Partenkirchen, Germany.

Evans, M. A., \& Wilkins, J. L. M., Ehrich, R. W., McNeill, D., \& Quek, F. (2009b). Second graders geometric reasoning with peers and manipulatives: Requirements for a multi-touch, tabletop learning technology. Paper presented at the American Educational Research Association Conference, San Diego, CA, April 13-17.

Evans, M. A., Wilkins, J. L. M., Motto, A., Brunger, A., \& Crider, J. (2011a). Group meaning in mathematical discourse: A multimodal analysis of prek students using multi-touch virtual manipulatives. In H. Spada, G. Stahl, N. Miyake, \& N. Law (eds.). Proceedings of the International Conference for Computer-Supported Collaborative Learning (Vol 11, pp.806-810). July 4-9, 2011, Hong Kong, China.

Evans, M. A., Feenstra, E., Ryon, E., \& McNeill, D. (2011b). A multimodal approach to coding discourse: Collaboration, distributed cognition, and geometric reasoning. International Journal of ComputerSupported Collaborative Learning, 6(2), 253-278.

Greenberg, S., Gutwin, C., \& Cockburn, A. (1996) Awareness Through Fisheye Views in Relaxed-WYSIWIS Groupware. Proceedings of Graphics Interface (pp. 28-38), Toronto, Canada, May 21-24. Morgan Kauffman.

Hatch, A., Higgins, S., \& Mercier, E. (2009). SynergyNet: Supporting Collaborative Learning in an Immersive Environment STELLAR Alpine Rendez-Vous Workshop 2009: "Tabletops for Education and Training" December 2-3, 2009, Garmisch-Partenkirchen.

Hoppe, H. U., Lingnau, A., Machado, I., Paiva, A., Prada, R., \& Tewissen, F. (2000). Supporting collaborative activities in computer integrated classrooms - the NIMIS Approach Proc. of 6th International Workshop on Groupware, CRIWG 2000. IEEE CS Press, Madeira, Portugal.

Inkpen, K. M., Ho-Ching, W., Kuederle, O., Scott, S., Shemaker, G. B.D. (1999). "This is fun! We're all best friends and we're all playing", Supporting Children's Synchronous Collaboration. In Proceedings of Computer Supported Collaborative Learning (CSCL) '99. Dec. 1999. Stanford, CA.

Jermann, P., Zufferey, G. \& Dillenbourg, P. (2008). Tinkering or sketching: Apprentices' use of tangibles and drawings to solve design problems. In Times of Convergence. Technologies Across Learning Contexts, Proceedings of ECTEL2008 (pp. 167-178). Berlin/Heidelberg: Springer, 2008.

Kaplan, F., Do Lenh, S., Bachour, K., Kao, G., Gault, C., \& Dillenbourg, P. (2008). Interpersonal computers for higher education. In P. Dillenbourg, J. Huang, \& M. Cherubini (Eds.), Collaborative artefacts and interactive furniture (pp. 129-146). Springer: Computer-Supported Collaborative Learning Series.

Kharrufa, A., Leat, D., \& Olivier, P. (2010a). Digital mysteries: Designing for learning at the tabletop. In Proceedings of ITS '10 (pp. 197-206). New York: ACM Press.

Kharrufa, A., Olivier, P., \& Leat, D. (2010b). Learning through reflection at the tabletop: A case study with digital mysteries. In Proceedings of EDMEDIA 2010 (pp. 665-674). Chesapeake, VA: AACE. 
Knight, J. K., \& Wood, W. B. (2005). Teaching more by lecturing less. Cell Biology Education, 4(4), $298-310$.

Koschmann, T. (1999). Computer support for collaboration and learning. The Journal of the Learning Sciences, 8, 495-497.

Leitão, S. (2000). The potential of argument in knowledge building. Human Development, 43, 332-360.

Li, S., Lv, J., Xu, Y., \& Jia, Y. (2007). EyeScreen: A gesture interface for manipulating on-screen objects. In J. A. Jacko (Ed.), HCI International 2007 - 12th International Conference - Part III 2007. pp. 710-717.

Lucchi, A., Jermann, P., Zufferey, G., \& Dillenbourg, P. (2010). An empirical evaluation of touch and tangible interfaces for tabletop displays. In Proceedings of the Fourth international Conference on Tangible, Embedded, and Embodied interaction (Cambridge, Massachusetts, USA, January 24-27, 2010). TEI '10. ACM, New York, NY, 177-184.

McNeill, D. (2006). Gesture and thought. Chicago: University of Chicago Press.

Nussbaum, M., Alvarez, C., Mcfarlane, A., Gomez, F., Claro, S., \& Radovic, D. (2009). Technology as small group face-to-face collaborative scaffolding. Computers in Education, 52, 147-153.

Nystrand, M., Wu, L., Gamoran, A., Zeiser, S., \& Long, D. (2003). Questions in time: Investigating the structure and dynamics of unfolding classroom discourse. Discourse Processes, 35(2), 135-198.

Olkun, S. (2003). Comparing computer versus concrete manipulatives in learning 2D geometry. Journal of Computers in Mathematics and Science Teaching, 22(1), 43-56.

Pangaro, G., Maynes-Aminzade, D., \& Ishii, H. (2002) The actuated workbench: Computer-controlled actuation in tabletop tangible interfaces, Proceedings of the 15th annual ACM symposium on User interface software and technology, October 27-30, Paris, France.

Piper, B., Ratti, C., \& Ishii, H. (2002). Illuminating Clay: A 3-D tangible interface for landscape analysis. In: Proceedings of the Conference on Human Factors in Computing Systems (CHI 2002), Minneapolis, Minnesota, April 2002. ACM Press, New York, pp. 355-362.

Rick, J., \& Rogers, Y. (2008). From DigiQuilt to DigiTile: Adapting educational technology to a multi-touch table. In Proceedings of TABLETOP’08 (pp. 79-86). Los Alamitos, CA: IEEE.

Rick, J., Marshall, P., \& Yuill, N. (2011). Beyond one-size-fits-all: How interactive tabletops support collaborative learning. In Proceedings of IDC '11. New York: ACM Press, (to appear)

Rogers, Y. (2006) Moving on from Weiser's vision of of calm computing: Engaging UbiComp experiences. In: P. Dourish and A. Friday (Eds.) Ubicomp 2006 Proceedings, LNCS 4206, pp. 404-421, Springer-Verlag,

Roschelle, J. (1992). Learning by collaborating: Convergent conceptual change. The Journal of the Learning Sciences, 2, 235-276.

Schellens, T., van Keer, H., Valcke, M., \& deWever, B. (2005). The impact of role assignment as scripting tool on knowledge construction in asynchronous discussion groups. In T. Koschmann, D. Suthers, \& T.W. Chan (Eds.), Computer-Supported collaborative learning 2005: The next 10 years (pp. 557-566). Mahwah: Lawrence Erlbaum.

Schmidt, K., \& Bannon, L. (1992). Taking CSCW seriously: Supporting articulation work. ComputerSupported Cooperative Work, 1, 7-40.

Schneider, B., Jermann, P., Zufferey, G., \& Dillenbourg, P. (2010). Benefits of a tangible interface for collaborative learning and interaction. IEEE Transactions on Learning Technologies.

Shaffer, D. (2005). Epistemic games. Innovate, 1(6). http://www.innovateonline.info/index.php? view $=$ article \&id $=79$.

Shen, C., Vernier, F., Forlines, C., \& Ringel, M. (2004). DiamondSpin: An extensible toolkit for around-thetable interaction. In Proceedings of the SIGCHI Conference on Human Factors in Computing Systems (CHI '04). ACM, New York, NY, USA, 167-174.

Shen, C., Vernier, F. D., Forlines, C., \& Ringel, M. (2004). DiamondSpin: An extensible toolkit for aroundthe-table interaction. Proc. of CHI'04, pp. 167-174.

Slavin, R. E. (1983). Cooperative learning. New York: Longman.

Stefik, M., Bobrow, D. G., Foster, G., Lanning, S., \& Tatart, D. (1987). WYSIWIS Revised: Early experiences with multiuser interfaces. ACM Transactions on Office Information Systems, 5(2), 147-167. April.

Stewart, J., Raybourn, E., Bederson, B. B., \& Druin, A. (1998). When two hands are better than one: Enhancing collaboration using single display groupware. In Proceedings of Extended Abstracts of Human Factors in Computing Systems (CHI 98) ACM Press, pp. 287-288

Streng, S., Stegmann, K., Wagner, C., Böhm, S., Hussmann, H., \& Fischer, F. (2011). Supporting argumentative knowledge construction in face-to-face settings: From ArgueTable to ArgueWall, Proceedings of the Conference on Computer-Supported Collaborative Learning 2011.

Sugimoto, M. (2009). Design of systems for supporting collaborative learning augmented with physical artefacts. In P. Dillenbourg, J. Huang, \& M. Cherubini (Eds.). Interactive Artifacts And Furniture Supporting Collaborative Work And Learning, Computer-Supported Collaborative Learning Series, Volume 10, 1-2. 
Sugimoto, M., Hosoi, K., \& Hashizume, H. (2004). Caretta: A system for supporting face-to-face collaboration by integrating personal and shared spaces. In Proceedings of CHI '04, pp. 41-48.

Suthers, D. D. (2006). Technology affordances for intersubjective meaning making: A research agenda for CSCL. International Journal of Computer-Supported Collaborative Learning, 1, 315-337.

Toulmin, S. (1958). The uses of argument. Cambridge: Cambridge University Press.

Underkoffler, J., \& Ishii, H. (1999). Urp: A luminous-tangible workbench for urban planning and design. In Proceedings of $\mathrm{CHI}$ '99, pp. 386-393.

Watanabe, K., Takeuchi, T., Inoue, T., \& Okada, K. (2008). Tangible tabletop interface that supports cooperative learning in face-to-face environment. Proceedings of ICCE 2008, pp. 463-467.

Weiser, M. (1991). The computer for the 21st century. Scientific American, 265(3), 94-104.

Winfield, L., Glassmire, J., Colgate, J. E., \& Peshkin, M. (2007). T-PaD: Tactile pattern display through variable friction reduction, world haptics conference, pp. 421-426, Second Joint EuroHaptics Conference and Symposium on Haptic Interfaces for Virtual Environment and Teleoperator Systems (WHC'07), 2007.

Zufferey, G., Jermann, P., Lucchi, A., \& Dillenbourg, P. (2009). TinkerSheets: Using paper forms to control and visualize tangible simulations. In Proceedings of TEI'09, Third International Conference on Embedded and Tangible Interaction, Cambridge (UK), February 16-18, 2009. 